\title{
Compound Heterozygous Variants in FAM111A Cause Autosomal Recessive Kenny-Caffey Syndrome Type 2
}

\author{
(D) Erdal Eren ${ }^{1}$, (D) Havva Tezcan Ünlü2 ${ }^{2}$, (D) Serdar Ceylaner ${ }^{3}$, (D) Ömer Tarım¹ \\ ${ }^{1}$ Bursa Uludağ University Faculty of Medicine, Department of Pediatric Endocrinology, Bursa, Turkey \\ 2Bursa Uludağ University Faculty of Medicine, Deparment of Medical Biology, Bursa, Turkey \\ 3Intergen Genetics Center, Ankara, Turkey
}

\begin{abstract}
What is already known on this topic?
Kenny-Caffey syndrome (KCS) is characterized by hypoparathyroidism, dwarfism, and dysmorphism. Osteocraniostenosis (OCS) is another syndrome similar to KCS. The autosomal dominant (AD) FAM111A mutation causes KCS2 and OCS syndrome; the perinatal and lethal forms should be kept in mind in the differential diagnosis. FAM111A is essential for parathyroid and bone formation; it might also be an essential factor in male genital development.
\end{abstract}

What this study adds?

To the best of our knowledge, this case is the first patient with genetically confirmed KCS2 or OCS in Turkey. It is known that the FAM111A mutation is transmitted in an AD manner. We present a case who showed autosomal recessive transmission. Unlike the known $\mathrm{AD}$ features of these syndromes, the cause of the patient's phenotype may be the identified compound heterozygous mutations of the FAM111A gene. The present patient probably has OCS, which is a severe form of KCS2.

\section{Abstract}

Kenny-Caffey syndrome (KCS) is a rare autosomal recessive (AR)/dominant disease characterized by hypoparathyroidism, skeletal dysplasia, dwarfism, and dysmorphism. FAM111A or TBCE gene mutations are responsible for this syndrome. Osteocraniostenosis (OCS) is a lethal syndrome with similar features to KCS, and it can be a severe form of KCS type 2 which results from the FAM111A gene mutation. The FAM111A mutation is generally characterized by the autosomal dominant transition. We present a male case having compound heterozygous variants (c.976T > A and c.1714_1716del) in the FAM111A gene with an AR inheritance pattern. Hypocalcemia developed on the second day of life. The patient and his older sister had a dysmorphic face, skeletal dysplasia, and they were diagnosed with hypoparathyroidism. Both siblings died due to septicemia. He is the first reported patient with the FAM111A mutation in Turkey. The phenotype of the patient is compatible with OCS, and the detected variants may explain the disease genetically.

Keywords: Hypoparathyroidism, skeletal dysplasia, osteocraniostenosis, short stature, dysmorphism, FAM111A gene, autosomal recessive

\section{Introduction}

Kenny-Caffey syndrome (KCS) is a rare autosomal recessive (AR) or dominant disease characterized by short stature, cortical thickening, medullary stenosis of the tubular bones, delayed closure of the anterior fontanel, eye abnormalities, and hypoparathyroidism (1). There are two inherent forms of KCS. While the AR form is caused by TBCE gene mutation, the autosomal dominant (AD) form results from FAM111A gene mutation. These gene mutations cause hypoparathyroidism, short stature, bone problems, and dysmorphic features $(2,3)$. Although knowledge about the FAM111A gene is limited, many cases presented in the literature show that FAM111A is an essential molecule for 
normal bone and parathyroid gland development. In this paper, we identified and present a patient with the FAM111A mutation using whole-exome sequencing (WES).

\section{Case Report}

A male patient was born as the third child of healthy, consanguineous ( $3^{\text {rd }}$ degree) parents at 38 weeks gestation, and skeletal dysplasia was suspected during the prenatal period. The grandfathers of the patient's mother and father are siblings. Except for the present patient and his sister, there was no family history with a similar disease. The patient's sister passed away due to hypocalcemia and sepsis at the age of 2 months.

The patient was admitted to hospital experiencing respiratory distress after birth. On physical examination, the child's weight was 2,770 grams [-1.4 standard deviation score (SDS)], his length was $44 \mathrm{~cm}(-2.73 \mathrm{SDS})$, and his head circumference was $34 \mathrm{~cm}$ (-0.64 SDS). Dysmorphic face (deep-set eyes, low set ear, microphthalmia, depressed nasal bridge), large anterior fontanel $(5 \times 6 \mathrm{~cm})$, short arm span, increased upper/lower ratio (2.2, the normal ratio is about 1.7), and micromelia were noted (Figure 1A). External genitalia was male, but micropenis (stretched penile length of $2.2 \mathrm{~cm})$ and low testicular volume $(2 \mathrm{~mL} / 2 \mathrm{~mL})$ were notable. There was no renal abnormality, and neurological examination was normal. The patient was admitted to

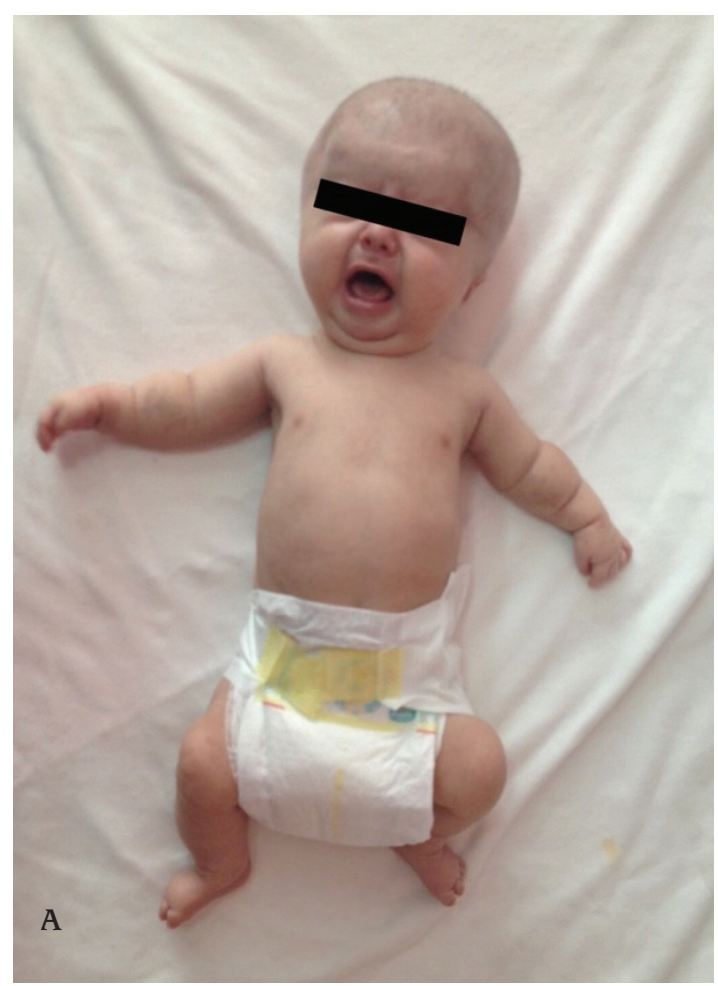

hospital due to respiratory distress. Hypocalcemia and hypoparathyroidism were detected [Ca $7.8 \mathrm{mg} / \mathrm{dL}$ (N: 8.511), P $9.3 \mathrm{mg} / \mathrm{dL}(\mathrm{N}: 5.6-10.5), \mathrm{PTH}<3 \mathrm{pg} / \mathrm{mL}(\mathrm{N}: 10-65)$, 25-OH vitamin D $37.8 \mathrm{mcg} / \mathrm{l}$ (N: 20-50)] on the second day, and oral calcium and calcitriol therapies were initiated. His calcium level was normalized two days after the start of treatment. The respiratory problems continued up to the $50^{\text {th }}$ day of life. Except for a tibial fracture noticed on the $38^{\text {th }}$ day, no further fracture was observed during follow-up.

Calcium administration was discontinued due to hypercalcemia on the $65^{\text {th }}$ day. The calcium level was not stable, and oral calcium treatment was continued intermittently. Low-dose calcitriol therapy was continued, but this treatment was ceased due to hypercalcemia. The patient was discharged on the $76^{\text {th }}$ day. In followup, hypoparathyroidism became evident again, and oral calcium and calcitriol therapies were commenced on the $85^{\text {th }}$ day. The patient was reluctant to feed and did not gain weight. He was readmitted to the intensive care unit with septicemia at the age of 3.5 months and died from respiratory failure after 30 days.

A skeletal survey showed incomplete ossification of the calvaria, short and thin ribs, hypoplastic thorax, and long thin bones (Figure 1B). He was diagnosed with KCS or Sanjad-Sakati syndrome (SSS) based on his clinical and radiological findings. Karyotype analysis was 46, XY and

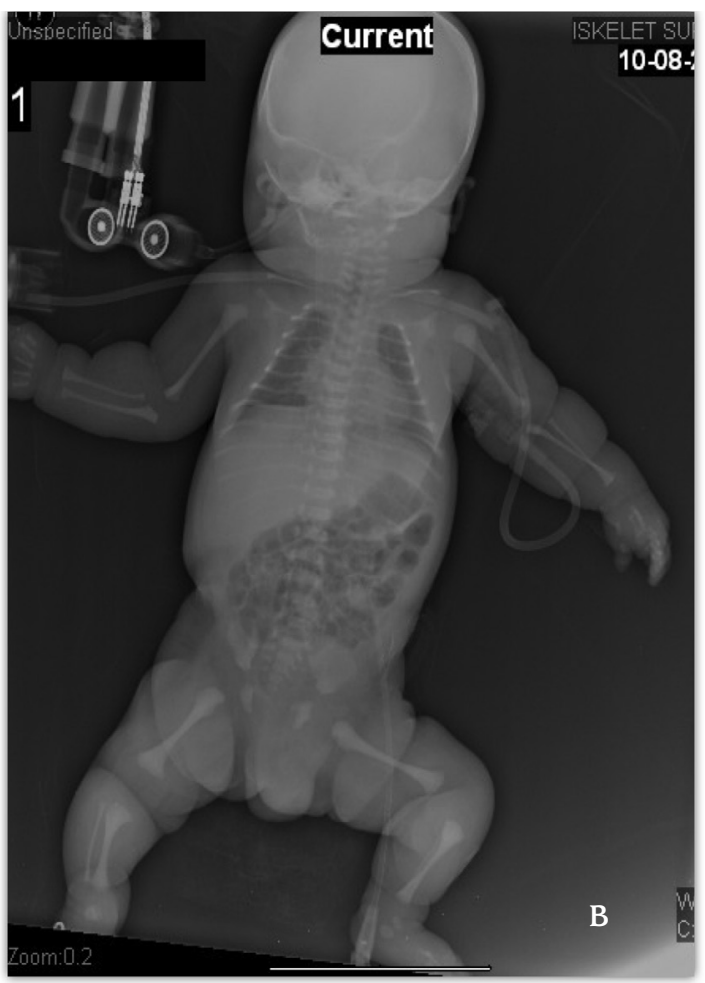

Figure 1. A) The general appearance of the patient (a relatively large head, small eyes, and inappropriate body size were noted) and B) Skeletal radiogram of the patient (narrowing, long, thin bones, and thin ribs were noted) 
FISH analysis for 22q11.2 deletion showed no abnormality. The patient's clinical features supported the initial diagnosis of SSS; however, TBCE exons Sanger sequencing revealed no abnormalities. WES was performed using peripheral blood genomic DNA from the patient and his parents. WES was performed by the Intergen Genetic Diagnosis Center in Ankara on a Miseq sequencing platform (Illumina, San Diego, CA, USA). After detecting the potential variants of the family, data analysis and bioinformatics processing were performed after receiving the primary sequencing data. The family history of the probands identified as carrying variants in the FAM111A is shown in the pedigree of Figure 2. The patient pedigree demonstrates that the inheritance pattern reveals AR transmission. After the data analysis, we identified compound heterozygous mutations of the FAM111A gene in the patient, including a paternal heterozygous missense variant c.976T > A (p.L326I) and a maternal heterozygous in-frame deletion variant c.1714_1716del (p.Ile572del, rs779963813) (Figure 3).

In this study, two variants were identified and examined in public databases (Ensembl, MutationTaster, Franklin, and Clinvar). Briefly, amino acid substitutions were identified with PROVEAN (http://provean.jcvi.org/), PolyPhen-2 (http:// genetics.bwh.harvard.edu/pph2/), and SIFT (http://sift. jcvi.org/) tools to determine the potential consequences of missense variants on protein function. The mutation taster (http://www.mutationtaster.org/) program was used to evaluate protein stability. The transcript number of the FAM111A gene is ENST00000528737.5. The c.1714_1716del mutation caused the FAM111A protein to lack only one amino acid, and the FAM111A: C.976T > A led to an amino acid change from leucine (Leu) to isoleucine (Ile).

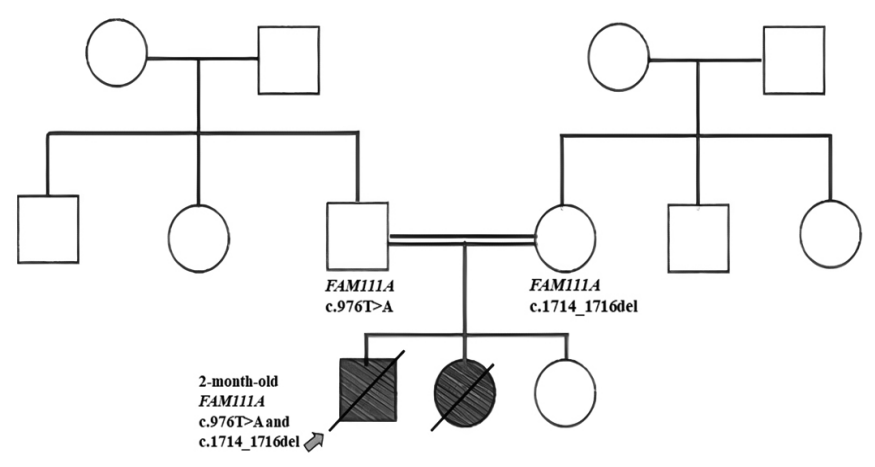

Figure 2. Family pedigrees of probands found to carry C.976T > A and c.1714_1716del compound heterozygous variants. Circles are females; squares are males. Filled symbol are affected with Kenny-Caffey syndrome

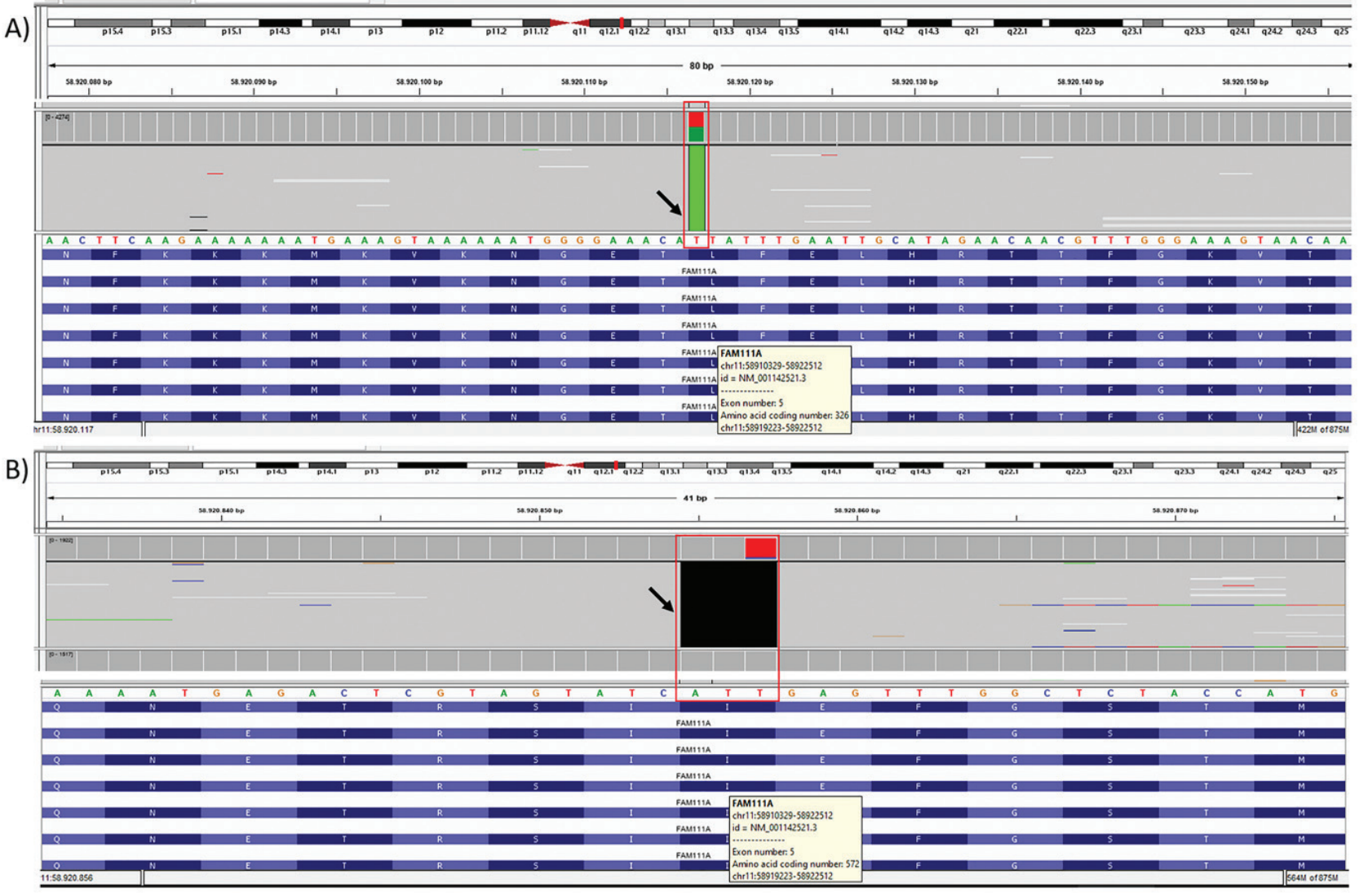

Figure 3. A schematic diagram of identified variants in the FAM111A gene, A) C.976T > A and B) C.1714_1716del in the index case 
A)

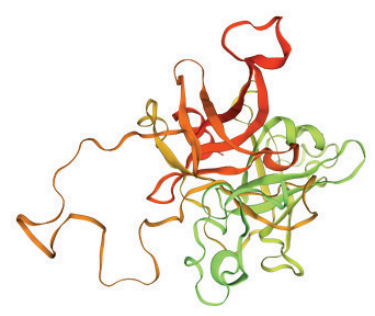

C)

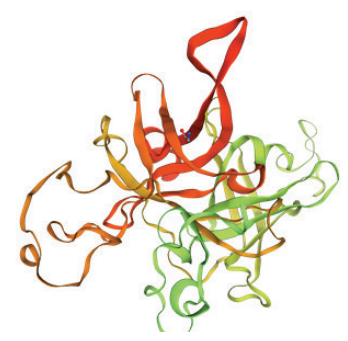

B)

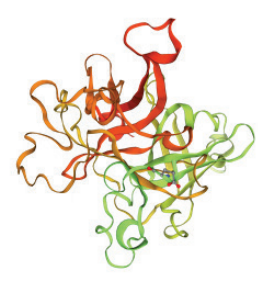

D)

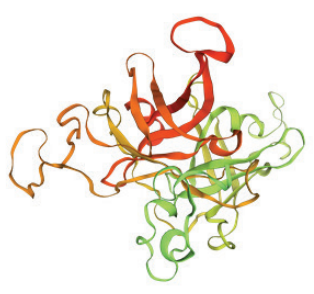

Figure 4. Figure shows the comparative 3D protein structure modeling (template 1.dua1., A) of FAM111A. The effect of $\quad$ C.976T $>$ A $\quad$ (B), C.1714_1716del $\quad$ (C), C.976T $>$ A, and C.1714_1716del together (D) variants on protein structure by the Swiss model, respectively. A wild-type, B, C, and D affected protein

The SWISS-MODEL used for tertiary structure prediction showed a marked variation in the structure of c.976T $>$ A and c.1714_1716del (Figure 4). Additionally, the p.Ile572del in the FAM111A gene was categorized as deleterious (score $=-11.79$ ) by PROVEAN Prediction and was presumed to be 'disease-causing' by Mutation Taster. The allele frequency of this variant is 9/251416 in the GnomAD exome database. In silico prediction tools other than Mutation Taster predicted this variant to be benign. Some other missense mutations are given very close to this mutation. Furthermore, the missense variant c.976T > A (p.L326I) in the FAM111A gene has not previously been reported in the literature, Ensembl genome databases, or Clinvar. The c.976T > A (p.Leu326Ile), a novel variant, was not found in the GnomAD exomes and GnomAD genomes database despite good coverage. This variant was classified as a variant of uncertain significance (VUS) (PM2, PP2, BP4). However, the results of bioinformatic prediction by PolyPhen 2 and SIFT confirmed that the amino acid substitution p.L326I in protein FAM111A was possibly damaging by PolyPhen $($ score $=0.635)$, tolerated by SIFT (score $=0.064$ ), and neutral by PROVEAN Prediction (score $=-1.05)$. Moreover, the variant was presumed to be a polymorphism by Mutation Taster; it was not found in ExAC and 1000G.

Additionally, the C.976T >A and C.1714_1716del variants were both stated to have "splice site changes" by Mutation Taster. However, these variants were classified as VUS by the Franklin variant classification tool (https://franklin.genoox.

com). As in the present case with a clinically clear picture, VUS and new/uncharacterized variants are notable because these variants can reveal unpredictable genetic and protein alterations involved in biochemical processes.

\section{Discussion}

We present a patient having a FAM111A variant which has not been previously reported as causing congenital hypoparathyroidism, dysmorphism, and/or skeletal dysplasia. KCS is classified into two types according to its clinical features and inheritance. Whereas the TBCE gene mutations are responsible for KCS type 1 (KCS1), the FAM111A gene mutation causes KCS type 2 (KCS2). SSS and KCS1 are AR syndromes characterized by hypoparathyroidism, mental retardation, facial dysmorphism, and extreme growth retardation.

The family with sequence similarity 111 , member A (FAM111 A or KIAA1895) gene is mapped on $11 \mathrm{q} 12.1$ and was first cloned by Nagase et al. (4) in 2001. The highest FAM111A expression is found in the adult spleen, followed by the adult kidney, lung, ovary, liver, pancreas, and fetal liver. The functions of FAM111A and FAM111B are still unknown, and knowledge of them is insufficient in the literature. The Swiss group firstly reported the FAM111A gene mutation in KCS2 patients in 2013 (2). They reported the R569H mutation in 4 out of the five patients who were from different countries. Isojima et al. (3) reported the R659H mutation in the FAM111A gene in three unrelated patients with KCS2.

It is stated that osteocraniostenosis (OCS) or gracile bone dysplasia can be considered a differential diagnosis of KCS2. OCS is characterized by thin, fragile, narrowing diaphyses, micromelic dwarfism, brachydactyly, facial dysmorphism, microphthalmia, and hypoparathyroidism. Unger et al. (2) reported on five KCS and five OCS patients. The authors speculated that KCS2 and OCS might both be allelic disorders of differing severity. OCS is a lethal perinatal condition and was named by Verloes et al. (5) in 1994. Thomas et al. (6) reported a lethal dysplasia in male and female siblings with severe pulmonary hypoplasia. These cases had pulmonary hypoplasia and required pulmonary support in the early period of their life. The patients (one who was genetically confirmed) died at 2 and 3.5 months. Most OCS patients died in the newborn period - only one survived to the age of 21 months in Unger et al.'s (2) series. Our case and his female sibling passed away due to pulmonary failure and septicemia at the age of 3.5 months and 2 months, respectively. The present case also had long, thin bones and ribs, as well as a tibial fracture. The long, thin bones may be related to hypoparathyroidism or insufficient 
bone development commensurate with the genetic defect's severity.

It has been postulated that FAM111A variants do not affect neural development, and therefore the affected patients would not present with developmental delay (2). In contrast, Cavole et al. (7) presented a patient with KCS2 having an intellectual disability and microcephaly. Our case had no neurological developmental delay and microcephaly, but the disease developed in the early prenatal period. OCS is a severe and life-threatening form, more so than KCS2, and so these cases might be labeled as OCS.

It is stated that KCS1 and SSS might be allelic disorders of differing severities (7). KCS2 and OCS may cause allelic disorders and have an overlapping phenotype. The differential diagnoses of some syndromes caused by TBCE and FAM111A mutation are shown in Table 1. KCS2 generally presents later in life, but OCS presents early. The clinical data suggest that our case had OCS because of a dysmorphic face, early-onset presentation, micromelia, long bone fracture, and disease severity. Our case had a micropenis. Unger et al. (2) stated that all OCS patients were male, and a micropenis was seen in 4 out of 5 cases. FAM111A might be an essential factor in male genital development, especially in OCS.

The c.976T > A and c.1714_1716del variants are reported as benign or VUS in prediction tools. In a large Chinese cohort of childhood-onset hypoparathyroidism (173 cases), 15 candidate genes were screened by NGS. They found a C.1706G > A (R569H) hotspot mutation in the FAM111A gene in a patient showing the pattern of KCS2. A novel heterozygous variant c.A881G/c.1714_1716del was reported in the same study (8). We found compound heterozygous variants (c.976T > A and c.1714_1716del) in our case. To date, almost 14 genetically confirmed cases

\begin{tabular}{|c|c|c|c|c|c|}
\hline & KCS1 & $\mathrm{KCS} 2$ & SSS & $\begin{array}{l}\text { Gracile bone } \\
\text { dysplasia }\end{array}$ & Index case \\
\hline Other name & & & HRD & OCS & \\
\hline Inheritance & AR & $\mathrm{AD}$ & AR & AD & AR \\
\hline Gene & $T B C E$ & FAM111A & $T B C E$ & FAM111A & FAM111A \\
\hline OMIM number & $\# 244460$ & \#127000 & \#241410 & \#602361 & \\
\hline Growth and height & $\begin{array}{l}\text { Short stature } \\
\text { Birth length }<3 \text { rd } \\
\text { percentile }\end{array}$ & Short stature, severe & $\begin{array}{l}\text { Severe intrauterine growth } \\
\text { retardation } \\
\text { Postnatal growth } \\
\text { retardation }\end{array}$ & $\begin{array}{l}\text { Short stature, severe } \\
\text { Failure to thrive }\end{array}$ & $\begin{array}{l}\text { Short stature, } \\
\text { severe }\end{array}$ \\
\hline Head, neck, skull & $\begin{array}{l}\text { Delayed anterior } \\
\text { fontanel closure } \\
\text { Hypertelorism } \\
\text { Dental caries } \\
\text { Poorly ossified skull } \\
\text { bones } \\
\text { Absent diploic space } \\
\text { Calvarial osteosclerosis }\end{array}$ & $\begin{array}{l}\text { Delayed anterior } \\
\text { fontanel closure } \\
\text { Macrocephaly } \\
\text { Prominent forehead } \\
\text { Hyperopia, } \\
\text { microphthalmia, } \\
\text { papilledema } \\
\text { Defective dentition } \\
\text { Osteosclerosis }\end{array}$ & $\begin{array}{l}\text { Microcephaly } \\
\text { Micrognathia } \\
\text { Prominent forehead, long } \\
\text { philtrum } \\
\text { Deep-set eyes } \\
\text { Low-set ears, posteriorly } \\
\text { rotated ears } \\
\text { Delayed bone age Patchy } \\
\text { osteosclerosis }\end{array}$ & $\begin{array}{l}\text { Prominent forehead } \\
\text { Microphthalmia } \\
\text { Cloverleaf-shaped } \\
\text { skull } \\
\text { Hypoplastic cranial } \\
\text { bones } \\
\text { Decreased } \\
\text { mineralization } \\
\text { of skull (in some } \\
\text { patients) }\end{array}$ & $\begin{array}{l}\text { Microphthalmia } \\
\text { Decreased } \\
\text { mineralization of } \\
\text { skull }\end{array}$ \\
\hline Limbs & $\begin{array}{l}\text { Medullary stenosis of } \\
\text { tubular bones } \\
\text { Thin long bones } \\
\text { Internal cortical } \\
\text { thickening } \\
\text { Small hands }\end{array}$ & $\begin{array}{l}\text { Thickened cortex of } \\
\text { long bones } \\
\text { Dense tubular bones } \\
\text { and narrow marrow } \\
\text { cavities }\end{array}$ & Small hands & $\begin{array}{l}\text { Micromelic short } \\
\text { limbs } \\
\text { Flared metaphyses } \\
\text { Long bone fractures } \\
\text { prenatally } \\
\text { Brachydactyly }\end{array}$ & $\begin{array}{l}\text { Micromelic short } \\
\text { limbs } \\
\text { Long bone fracture }\end{array}$ \\
\hline Genitourinary & & Microorchidism & Microorchidism & Micropenis & Micropenis \\
\hline Endocrine & $\begin{array}{l}\text { Neonatal } \\
\text { hypoparathyroidism, } \\
\text { low parathyroid } \\
\text { hormone }\end{array}$ & $\begin{array}{l}\text { Low parathyroid } \\
\text { hormone, low } \\
\text { calcitonin } \\
\text { Small to absent } \\
\text { parathyroid glands }\end{array}$ & $\begin{array}{l}\text { Low parathyroid hormone } \\
\text { Congenital } \\
\text { hypoparathyroidism }\end{array}$ & $\begin{array}{l}\text { Hypocalcemia } \\
\text { Low parathyroid } \\
\text { hormone }\end{array}$ & $\begin{array}{l}\text { Hypocalcemia } \\
\text { Low parathyroid } \\
\text { hormone }\end{array}$ \\
\hline $\begin{array}{l}\text { Immune, } \\
\text { hematological }\end{array}$ & $\begin{array}{l}\text { Recurrent bacterial } \\
\text { infections } \\
\text { Anemia }\end{array}$ & Anemia & $\begin{array}{l}\text { Recurrent bacterial } \\
\text { infections }\end{array}$ & $\begin{array}{l}\text { Recurrent bacterial } \\
\text { infections }\end{array}$ & Anemia \\
\hline Neurological deficit & Yes, usually & No, usually & Yes, usually & Yes & No \\
\hline
\end{tabular}


have been presented, but knowledge about KCS2 or OCS is still limited. Detected variants in the FAM111A gene should be published in the literature in order to reveal genotypephenotype correlations. The phenotype of the present case was compatible with OCS, and the variants presented may explain the disease genetically. The relationship between genotype and phenotype will be further enlightened with more cases presented in the literature.

\section{Conclusion}

There is limited knowledge about the FAM111A gene. Some genetically unconfirmed KCS patients can have the FAM111A gene mutation. The FAM111A mutation is generally characterized by AD transmission. Our study patient had compound heterozygous variants (c.976T > A and C.1714_1716del) in the FAM111A gene with an AR inheritance pattern. Our study case probably had OCS, which is a severe form of KCS2. OCS or KCS2 should be suspected in a hypocalcemic neonatal/infantile patient with short stature and facial dysmorphism.

\section{Ethics}

Informed Consent: Consent form was filled out by all participants.

Peer-review: Externally peer-reviewed.

\section{Authorship Contributions}

Surgical and Medical Practices: Erdal Eren, Ömer Tarım, Concept: Erdal Eren, Havva Tezcan Ünlü, Data Collection or Processing: Erdal Eren, Havva Tezcan Ünlü, Serdar Ceylaner, Analysis or Interpretation: Serdar Ceylaner, Erdal Eren, Havva Tezcan Ünlü, Literature Search: Erdal Eren, Ömer Tarım, Writing: Erdal Eren, Ömer Tarım.
Financial Disclosure: The authors declared that this study received no financial support.

\section{References}

1. Caffey J. Congenital stenosis of medullary spaces in tubular bones and calvaria in two proportionate dwarfs--mother and son; coupled with transitory hypocalcemic tetany. Am J Roentgenol Radium Ther Nucl Med 1967;100:1-11.

2. Unger S, Górna MW, Le Béchec A, Do Vale-Pereira S, Bedeschi MF, Geiberger S, Grigelioniene G, Horemuzova E, Lalatta F, Lausch E, Magnani C, Nampoothiri S, Nishimura G, Petrella D, Rojas-Ringeling F, Utsunomiya A, Zabel B, Pradervand S, Harshman K, Campos-Xavier B, Bonafé L, Superti-Furga G, Stevenson B, Superti-Furga A. FAM111A mutations result in hypoparathyroidism and impaired skeletal development. Am J Hum Genet 2013;92:990-995. Epub 2013 May 16

3. Isojima T, Doi K, Mitsui J, Oda Y, Tokuhiro E, Yasoda A, Yorifuji T, Horikawa R, Yoshimura J, Ishiura H, Morishita S, Tsuji S, Kitanaka S. A recurrent de novo FAM111A mutation causes Kenny-Caffey syndrome type 2. J Bone Miner Res 2014;29:992-998.

4. Nagase T, Kikuno R, Ohara O. Prediction of the coding sequences of unidentified human genes. XXI. The complete sequences of 60 new cDNA clones from brain which code for large proteins. DNA Res $2001 ; 8: 179-187$

5. Verloes A, Narcy F, Grattagliano B, Delezoide AL, Guibaud P, Schaaps JP, Le Merrer M, Maroteaux P. Osteocraniostenosis. J Med Genet 1994;31:772-778

6. Thomas JA, Rimoin DL, Lachman RS, Wilcox WR. Gracile bone dysplasia. Am J Med Genet 1998;75:95-100.

7. Cavole TR, Perrone E, de Faria Soares MF, Dias da Silva MR, Maeda SS, Lazaretti-Castro M, Alvarez Perez AB. Overlapping phenotype comprising Kenny-Caffey type 2 and Sanjad-Sakati syndromes: The first case report. Am J Med Genet A 2020;182:3029-3034. Epub 2020 Oct 3

8. Wang $\mathrm{Y}$, Nie $\mathrm{M}$, Wang $\mathrm{O}$, Li $\mathrm{Y}$, Jiang $\mathrm{Y}$, Li $\mathrm{M}$, Xia $\mathrm{W}$, Xing $\mathrm{X}$. Genetic Screening in a Large Chinese Cohort of Childhood Onset Hypoparathyroidism by Next-Generation Sequencing Combined with TBX1-MLPA. J Bone Miner Res 2019;34:2254-2263. Epub 2019 Nov 13 